\title{
Fruit visitation patterns of small mammals on the forest floor in a tropical seasonal forest of Thailand
}

\author{
Shunsuke Suzuki ${ }^{1}$, Shumpei Kitamura ${ }^{2,3}$, Masahiro Kon ${ }^{1}$, Pilai Poonswad ${ }^{3}$, Phitaya Chuallua ${ }^{3}$, Kamol Plongmai ${ }^{3}$, Takakazu \\ YUMOTO $^{2,4}$, Naohiko Noma ${ }^{1}$, Tamaki MARUhashi ${ }^{5}$ and Prawat WoHANDEE ${ }^{6}$ \\ ${ }^{1}$ School of Environmental Science, The University of Shiga Prefecture, Hikone, 522-8533, Japan \\ ${ }^{2}$ Center for Ecological Research, Kyoto University, Kamitanakami-Hirano, Otsu, 520-2113, Japan \\ ${ }^{3}$ Thailand Hornbill Project, Department of Microbiology, Faculty of Science, Mahidol University, Bangkok 10400, Thailand \\ ${ }^{4}$ Research Institute of Humanity and Nature, 457-7, Motoyama, Kamigamo, Kita-ku, Kyoto, 602-0878, Japan \\ ${ }^{5}$ Department of Human and Culture, Musashi University, Nerima, Tokyo 176-8534, Japan \\ ${ }^{6}$ National Park, Wildlife and Plant Conservation Department, Bangkok 10900, Thailand \\ Correspondence address: \\ Shunsuke SUZUKI \\ Tel: +81-749-28-8311, Fax: +81-749-28-8477, E-mail: s11ssuzuki@ec.usp.ac.jp
}

\begin{abstract}
The fruit visitation patterns of small mammals were investigated by camera trappings on the forest floor in a tropical seasonal forest of Thailand. A total of 3,165 visits were recorded for seven small mammal species. The four Muridae species, Rattus remotus, Niviventer fulvescens, Leopoldamys sabanus and Maxomys surifer, all of which were nocturnal, were almost completely temporally segregated from the tree shrew, Tupaia belangeri, and the two squirrels, Callosciurus finlaysonii and Menetes berdmorei, which were diurnal or crepuscular. We suggest that the temporal segregation reduced the interference competition between the four Muridae species and the tree shrew or squirrel for fruits on the forest floor. In addition, the visitation patterns for fruit species differed among the four Muridae species and between the tree shrew and the two squirrels, suggesting that the variation in the visitation patterns for fruit species helped to facilitate coexistence among these species. In contrast, the two squirrels were similar in their visitation patterns, both temporally and in their choice of fruit species.
\end{abstract}

Key words: coexistence, crepuscular, diurnal, frugivore, Khao Yai National Park, nocturnal, small mammal, temporal segregation

\section{INTRODUCTION}

Tropical forests are enormously diverse and complex habitats and harbor many species of mammals and birds, (Harrison, 1962; Miura et al. 1997), including small mammals (Robinson et al. 1995; Wu et al. 1996; Yasuda et al. 2003; Pardini, 2004). The species richness and abundance of small mammals in tropical forests can be attributed to affluent food resources, especially the abundant fruit crops (Fleming, 1973; August, 1983; Wells et al. 2004). Terrestrial small mammals are considered to have effects on tropical forest ecosystems as seed and seedling predators and seed dispersers (Adler and Kestell, 1998; Asquith et al. 1999; Guariguata et al. 2000). In recent years, the abundance of large animal species has declined and communities have been altered due to habitat loss or fragmentation in tropical forests (Soule et al. 1992; Laidlaw, 2000; Sodhi et al. 2004). Small mammal species, however, are adaptable enough to inhabit in various and patchy environments and are more robust in dealing with habitat changes. In order to predict the fate of fragmented or disturbed forests, it is important to understand the coexistence patterns of small mammal assemblages in relation to their roles in tropical forest ecosystems (Wells et al. 2004).

The coexistence of sympatric species can be facilitated by the differentiation in niche dimensions, such as habitat, food and time (Schoener, 1974; M'Closkey, 1976). There have been several studies on microhabitat utilization and segregation of small mammal assemblages in tropical forests (Shanker, 2001; Wells et al. 2004). While there have been some studies on food resource partitioning in rodents in the desert (e.g. Brown et al. 1979; Brown, 1989), there have been very few on small mammals in tropical forests (Emmons, 1980; Smythe, 1986). Moreover, little is known about temporal differentiation of food resource utilization. This is 
partly due to the difficulty in observing the often cryptic behavior of small mammals. Temporal differentiation in food resource utilization can be recorded by various methods, including radio telemetry, consecutive trapping, direct observation and camera trapping. In recent years, remarkable improvements have been made for various wildlife studies through the use of camera trapping (Griffiths and van Schaik, 1993; Miura et al. 1997; Blanchong and Smale, 2000; Jayasekara et al. 2003; O’Brien et al. 2003; Kawanishi and Sunquist, 2004; Yasuda et al. 2005). Camera trapping can provide precise time data for visitation patterns of animals, which can be quantitatively analyzed for visitation time and resource utilization patterns (Yasuda et al. 2005).

Through the use of camera trappings, the relationships between fruits and frugivores on the forest floor of a tropical forest were studied in Khao Yai National

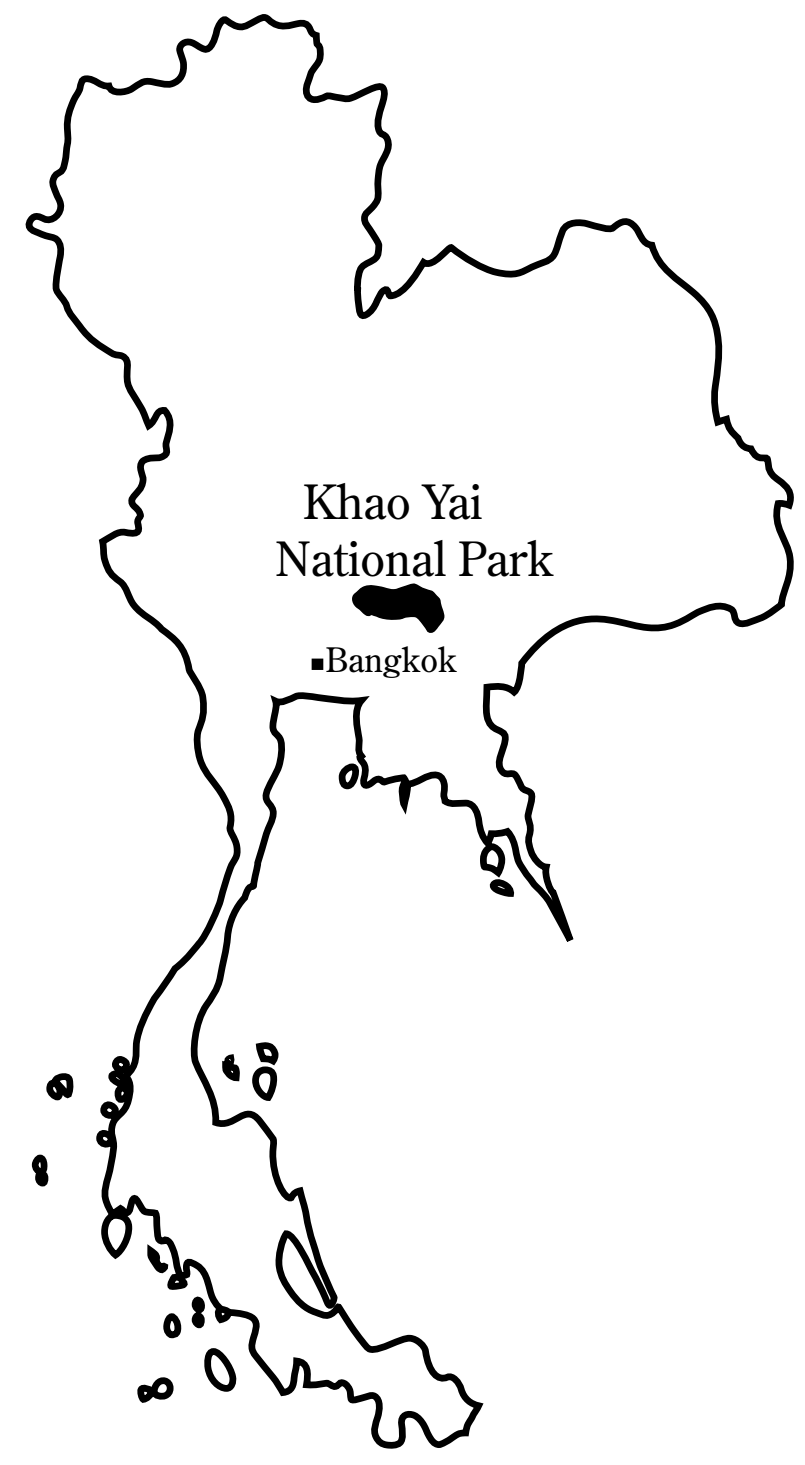

Fig. 1. Location of Khao Yai National Park
Park in Thailand. We obtained a large number of pictures of small mammals visiting the fruit bait on the forest floor. In this paper, we examine the differentiation in the fruit visitation patterns among small mammal species that utilize fruits on the forest floor, and compare the distribution of these patterns between small mammal species, both temporally and in terms of fruit species.

\section{MATERIALS AND METHODS}

Study site

The study was carried out in Khao Yai National Park (hereafter KY; Fig. 1) in lower northeastern Thailand. The park ranges from $14^{\circ} 05^{\prime} \mathrm{N}$ to $14^{\circ} 15^{\prime} \mathrm{N}$ and from $101^{\circ}$ $05^{\prime} \mathrm{E}$ to $101^{\circ} 50^{\prime} \mathrm{E}$ in the Dongruk mountain range, and covers an area of $2,168 \mathrm{~km}^{2}$. Its elevation ranges from 250 to $1,351 \mathrm{~m}$. The main study site was adjacent to the headquarters of KY and covered about $70 \mathrm{~km}^{2}$. The area ranges from 600 to $800 \mathrm{~m}$ in altitude and is covered by moist evergreen forest. The annual mean rainfall is 2,360 mm (1993-2002); the wet season usually occurs from April to October and the dry season is from November to March (Kitamura et al. 2004). The monthly mean temperature ranges from $21^{\circ} \mathrm{C}$ (December and January) to $32^{\circ} \mathrm{C}$ (April and May).

In the study area, sunrise is between $0545 \mathrm{~h}$ and $0643 \mathrm{~h}$ throughout a year and sunset is between $1743 \mathrm{~h}$ and $1847 \mathrm{~h}$. According to the standard time near KY, we divided a day into the following three time zones: daytime from $0700 \mathrm{~h}$ to $1700 \mathrm{~h}$; nighttime from $1900 \mathrm{~h}$ to $0500 \mathrm{~h}$; and crepuscular time from $0500 \mathrm{~h}$ to $0700 \mathrm{~h}$ and $1700 \mathrm{~h}$ to $1900 \mathrm{~h}$.

Although ripe fruits (e.g. Ficus spp.) are available year-round (Poonswad et al. 1998), fruit diversity and abundance are relatively high in the rainy season and reach a trough at the beginning of the dry season (Bartlett 2003). Trees reach $45 \mathrm{~m}$ in height; the density of trees over $10 \mathrm{~cm}$ in diameter at breast height (DBH) is 371 $\mathrm{ha}^{-1}$, with a basal area of $32 \mathrm{~m}^{2} \mathrm{ha}^{-1}$. The dominant plant families in the forest include the Lauraceae, Cornaceae, Euphorbiaceae, Meliaceae, Dipterocarpaceae, and Annonaceae. Kitamura et al. (2005) provided a detailed botanical inventory.

\section{Photographing by automatic camera systems}

We conducted surveys on the fruit visitation patterns of small mammals from July 2000 to June 2002 using automatic camera systems. We used two kinds of systems, both of which consist of a far-infrared sensor, motor-driven compact camera with a built-in flash and 
a data pack that stamps each picture with the date and time of exposure. The system used until June 2001 was developed by Miura et al. (1997). From April 2001, we used a Sensor Camera "FIELDNOTE" (MARIF Co. Ltd, Japan; Yasuda, 2004). The cameras were checked at an interval of 1 to 3 days, and films (ISO 100 or ISO 400, 36 exposures) and batteries (CR123A lithium battery) were renewed if necessary.

We used the fruits of 186 individuals of 67 plant species as baits. Five to 50 fruits that had been collected from the ground or trees were set on the ground under the source tree as bait, and a camera was placed about 2 $\mathrm{m}$ apart from the bait fruits. When the bait fruits were consumed by animals or damaged by insects or microbes, they were replaced with new ones. The photographing duration varied from 5 to 90 consecutive days according to the period when fruits were available from each individual tree. Based on the pictures, we recorded when and what small mammals visited the bait fruits. We followed Corbet and Hill (1992) for the taxonomic nomenclature of small mammals.

Because the cameras were triggered every 10 to 15 seconds while an animal or group of animals was within the detectable area of the sensor, one picture does not necessarily represent a single visit of a given animal species. We regarded a picture as one visit by a given species only when the picture was taken more than 30 minutes after the last picture of the same species (O'Brien et al. 2003, Yasuda, 2004).

\section{Similarity in the temporal distribution of visits}

Similarity in the temporal distribution of visits between a given pair of animal species was measured using Pianka's $\alpha$ index as follows (Pianka, 1973):

$$
\alpha_{j k}=\frac{\sum_{i} p_{i j} p_{i k}}{\sqrt{\sum_{i}\left(p_{i j}\right)^{2} \sum_{i}\left(p_{i k}\right)^{2}}}
$$

where $p_{i j}$ is the proportion of visits during an hour $i$ ( $i=0$ $-23 \mathrm{~h}$ ) to the total visits for animal species $j$ and $p_{i k}$ is that for animal species $k$. This index ranges between 0 and 1 , and similarity increases as the index approaches 1 .

Not all small mammal species investigated in the present study necessarily utilized all the fruit species. However, if both of two given mammal species were observed to visit a given fruit species, we considered that they potentially competed with each other for the fruit species (although the intensity of competition could have changed with the relative abundance of the fruit species). Therefore, similarity in the temporal distributions of visits between a given pair of animal species was analyzed based only on the data for the fruit species that had been visited by both animal species.

\section{Similarity in the visitation pattern for fruit species} Similarity in the rank order for the number of visits per day to a fruit species was measured for each pair of animal species using Spearman's rank correlation. If both of two given animal species have the same rank order, then the rank correlation coefficient culminates in 1 ; if animals have a completely inverse rank order, it is -1 ; and if independent of each other, it is 0 .

\section{RESULTS}

Forty-eight animal species were identified from 11,079 pictures. Among them, eight small mammal species were included, but one species (Crocidura horsfildi) was excluded from further analyses due to the small sample size (< 10 visits). The remaining seven species were recognized from 5,419 pictures. From the pictures of small mammal species, 3,165 (58.4\%) were regarded as independent visits and used for further analyses. Of these species, the yellow rajah rat, Maxomys surifer, visited most frequently, followed by the Indochinese ground squirrel, Menetes berdmorei (Table 1). The visits of these two species accounted for $82.4 \%$ of all the visits by the target species.

The Finlayson's squirrel, Callosciurus finlaysonii, visited the bait fruits mainly in the daytime with a peak in the afternoon; about $90 \%$ of its visits were recorded in the daytime whereas there were no visits in the nighttime (Fig. 2a, Table 1). Hereafter we regard this species as 'diurnal'. In contrast, the Indochinese ground squirrel, Menetes berdmorei, and the northern tree shrew, Tupaia belangeri, visited bait fruits bimodally with peaks (more than $50 \%$ of their visits) at dawn and dusk crepuscular time (Fig. $2 \mathrm{~b}$ and c, Table 1). Hereafter we regard these species as 'crepuscular'. All four Muridae species visited the bait fruits mainly in the nighttime when more than $90 \%$ of their visits were recorded, and there were no visits in the daytime (Fig. $2 d-g$, Table 1). Hereafter we regard these species as 'nocturnal'.

Similarities in the temporal distribution of visits were low ( $\alpha=0.000-0.043$ ) for species pairs between the four Muridae species and the tree shrew or squirrels (Table 2 ), whereas they were high for a pair of crepuscular species and those of nocturnal species ( $\alpha=0.678-0.983)$. Intermediate values were observed between diurnal and crepuscular species ( $\alpha=0.398$ for Tupaia belangeri and Callosciurus finlaysonii; $a=0.478$ for Callosciurus 
Table 1. Classification of small mammals based on the temporal distribution of visits.

\begin{tabular}{llcrrrrr}
\hline Family & Scientific name & $\begin{array}{c}\text { No. of } \\
\text { pictures }\end{array}$ & $\begin{array}{c}\text { Total } \\
\text { visits }\end{array}$ & Daytime & $\begin{array}{c}\text { Crepuscula } \\
\text { r time }\end{array}$ & Nighttime & Category \\
\hline Sciuridae & Callosciurus finlaysonii & 307 & 106 & $99(93.4)$ & $7(6.6)$ & $0(0.0)$ & Diurnal \\
& Menetes berdmorei & 1119 & 527 & $209(39.7)$ & $318(60.3)$ & $0(0.0)$ & Crepuscular \\
Tupaiidae & Tupaia belangeri & 192 & 121 & $54(44.6)$ & $67(55.4)$ & $0(0.0)$ & Crepuscular \\
Muridae & Rattus remotus & 85 & 63 & $0(0.0)$ & $3(4.8)$ & $60(95.2)$ & Nocturnal \\
& Niviventer fulvescens & 278 & 194 & $0(0.0)$ & $17(8.8)$ & $177(91.2)$ & Nocturnal \\
& Leopoldamys sabanus & 120 & 73 & $0(0.0)$ & $0(0.0)$ & $73(100.0)$ & Nocturnal \\
& Maxomys surifer & 3318 & 2081 & $0(0.0)$ & $134(6.4)$ & $1947(93.6)$ & Nocturnal \\
\hline
\end{tabular}

No. of pictures: the total number of pictures of each small mammal species

Total visits: the total number of visits

Daytime: the number of visits recorded during the daytime

Crepuscular time: the number of visits recorded during the crepuscular time

Nighttime: the number of visits recorded during the nighttime

The percentage to the total number of visits is shown in the parenthesis.

\section{finlaysonii and Menetes berdmorei; Fig. 3a).}

Fig. 3 shows the number of visits per day of each small mammal species for the representative fruit species. The fruit species most frequently visited differed among small mammal species. Moreover, the rank orders for the number of visits to a fruit species per day were not highly positively correlated for most pairs of animals ( $\mathrm{rs}=-0.031$ to 0.359 ; Table 2). The highest correlation was observed between Tupaia belangeri and Rattus remotus $\left(r_{\mathrm{s}}=0.359\right.$, $\mathrm{P}<0.01, \mathrm{~N}=63$ ), followed by $T$. belangeri and Leopoldamys sabanus $\left(\mathrm{r}_{\mathrm{s}}=0.268, \mathrm{P}<0.05, \mathrm{~N}=63\right)$ and Callosciurus finlaysonii and Menetes berdmorei $\left(\mathrm{r}_{\mathrm{s}}=0.251, \mathrm{P}<0.05\right.$, $\mathrm{N}=63$ ). There was no significant correlation between any the other pairs of animal species.

\section{DISCUSSION}

The temporal distribution of visits observed in the present study are regarded as representing the food searching activity pattern of each small mammal species, because we recorded their visits by attracting them with bait fruits. Differentiation in the temporal distribution of visits between the four Muridae species and the other three diurnal or crepuscular species is likely to have contributed to a reduction in interference competition for fruits on the forest floor. Moreover, if fruits supply is limited, the temporal differentiation in food searching activities could also affect exploitative competition between these species, depending on the timing of when fruits fall to the ground.

The four Muridae species resembled each other closely in their temporal distribution of visits, but not in their visitation patterns for each fruit species. Therefore, the differentiation in the preference of fruit species could have promoted coexistence among these species. However, we note that the fruit species visitation pattern recorded in the present study may not represent the resource utilization curve of a given mammal species, because we had no data on the relative abundance of each fruit species.

The two squirrel species more or less resembled each other in both their temporal distribution of visits and visitation patterns for each fruit species (Table 2). However, $C$. finlaysonii usually inhabits the middle storey of a forest canopy and is rarely found on the ground (Srikosamatara and Hansel, 1996), whereas M. berdmorei stays mainly on the ground (Lekagul and McNeely, 1977). Thus, these two squirrel species may be segregated vertically rather than temporally or for fruit species.

The ground squirrel, Menetes berdmorei, and the tree shrew, Tupaia belangeri, were crepuscular in this study and are known to forage mainly on the ground (Lekagul and McNeely, 1977; Emmons, 2000). However, they appeared to be segregated in their visitation pattern for fruit species (Table 2, Figs. 2b and c). Menetes berdmorei frequently visited hard covered fruits such as Canarium euphyllum, Lithocarpus thomsonii, and Beilschmiedia villosa, whereas the tree shrew rarely visited them. It could be because $M$. berdmore $i$ has well-developed incisor teeth whereas $T$. belangeri does not. In addition, $T$. belangeri also differed from another squirrel species, $C$. finlaysonii, in its visitation pattern for fruit species (Table 2). This appeared partly because C. finlaysonii also visited C. euphyllum frequently. 
b. Callosciurus finlaysonii

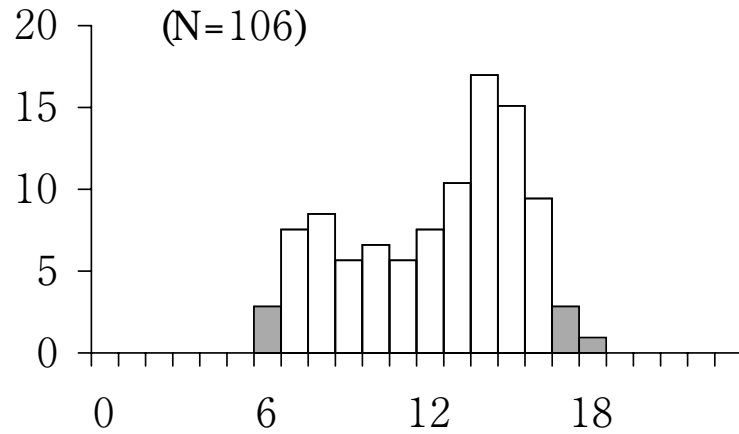

a. Tupaia belangeri

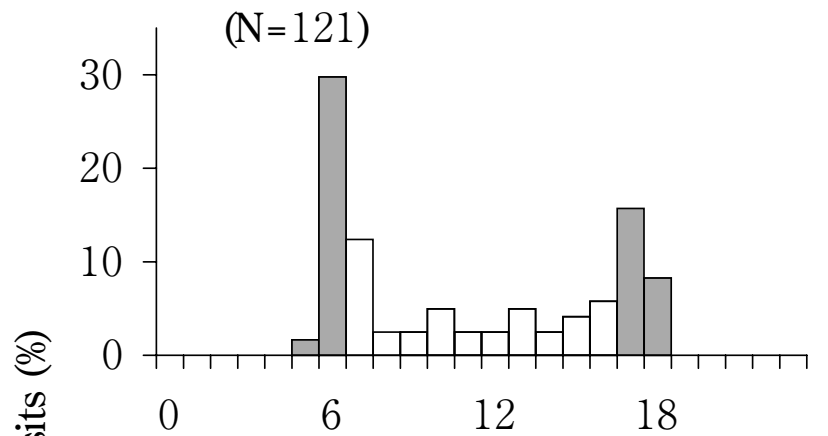

c. Menetes berdmorei

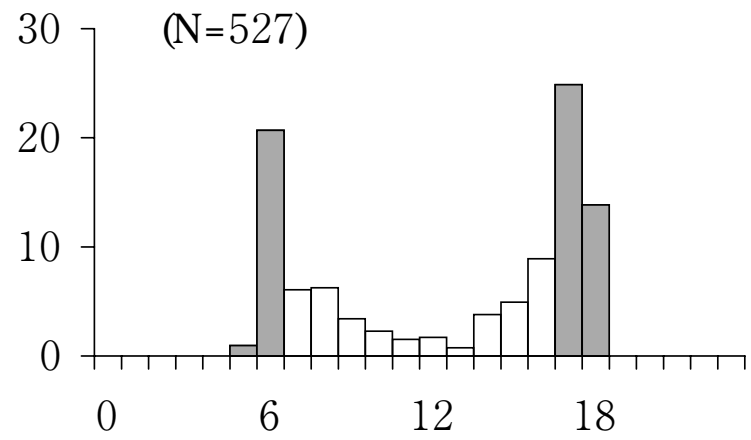

d. Rattus remotus

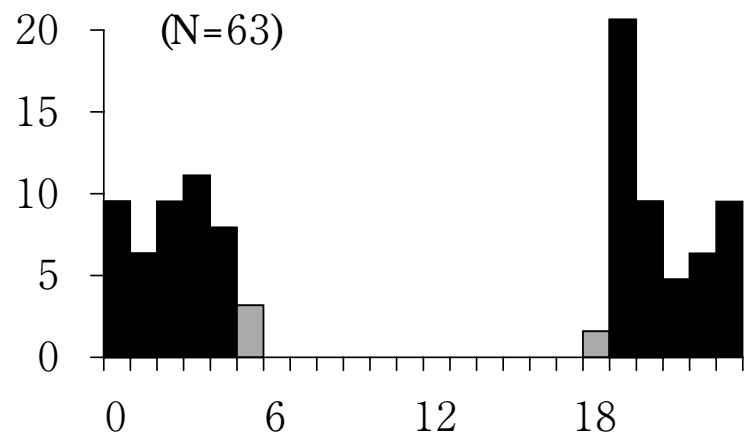

f. Leopoldamys sabanus

e. Niviventer fulvescens

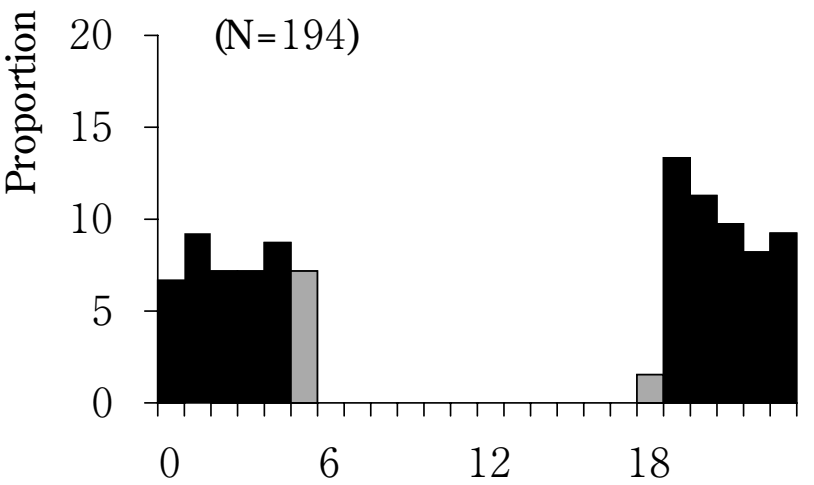

g. Maxomys surifer

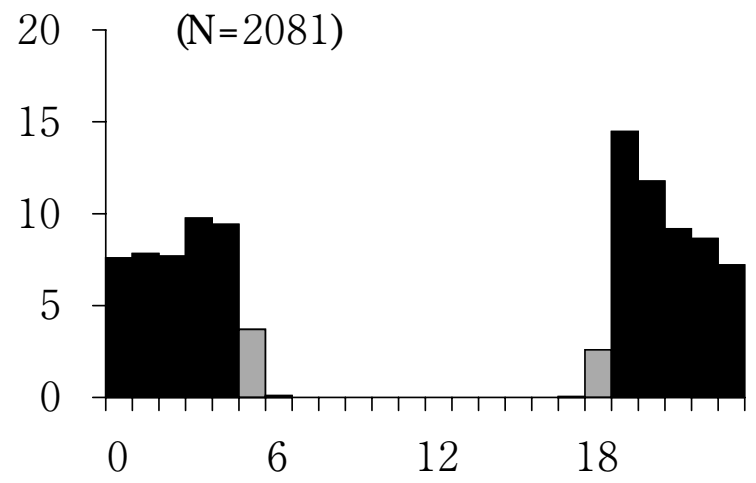

Time of day (hour)

Fig. 2. Temporal distribution of visits by the seven small mammal species. Open column: daytime, gray column: crepuscular time, closed column: nighttime. 

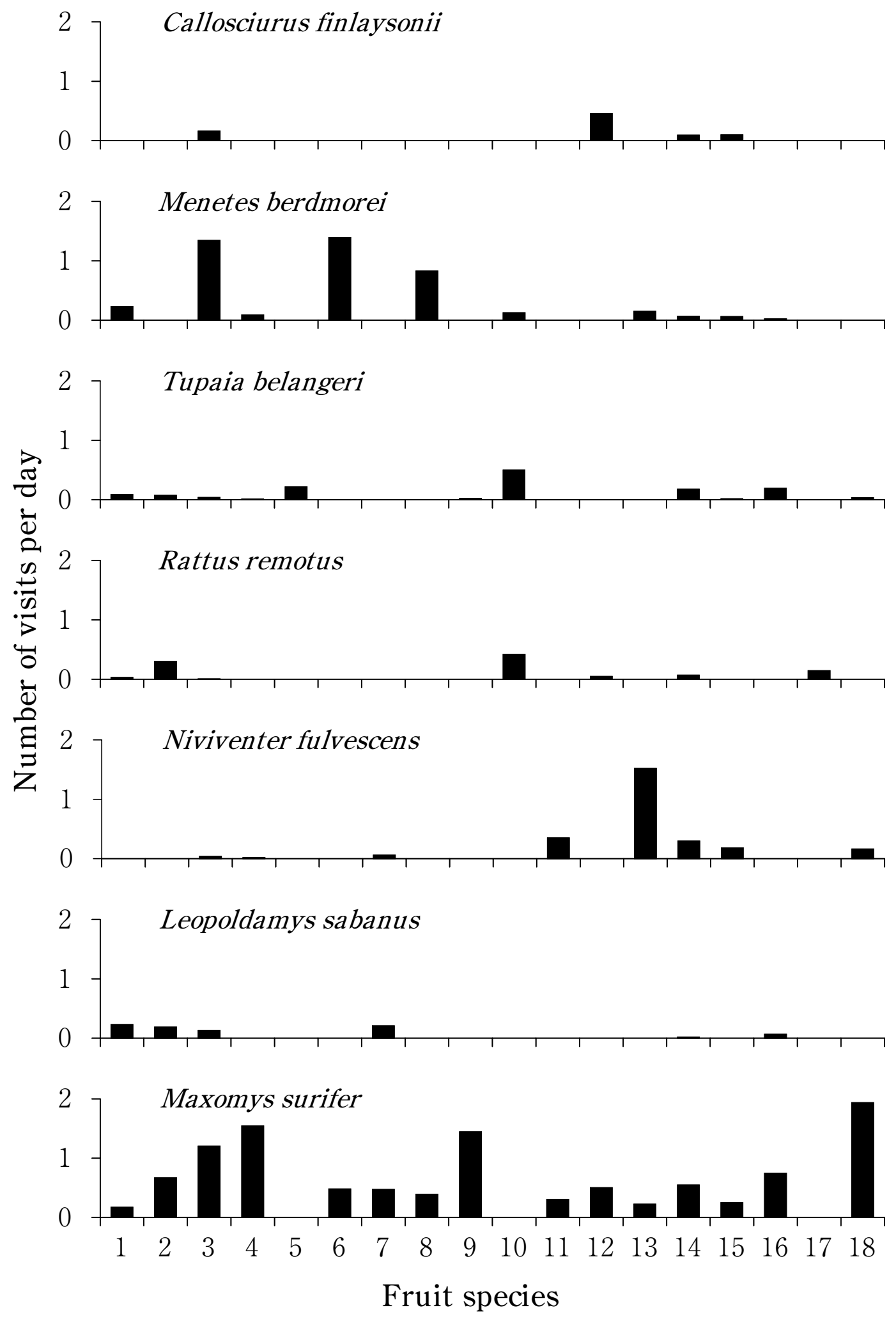

Fig. 3. The number of visits per day of each small mammal specie for representative fruit species, including the three fruit species that each mammal species visited most frequently. 1. Alphonsea cf. cylindrica, 2. Miliusa lineata, 3. Canarium euphyllum, 4. Mastixia pentandra, 5. Euphorbiaceae sp., 6. Lithocarpus thomsonii, 7. Gonocarium lobbianum, 8. Beilschmiedia villosa, 9. Cryptocarya cf. impressa, 10. Phoebe cathia, 11. Acrocarpus fraxinifolius, 12. Aglaia lawii, 13. Ficus benjamina, 14. Ficus subcordata, 15. Anthocephalus chinensis, 16. Canthium coffeoides, 17. Citrus limon, 18. Mischocarpus pentapetalus. 
Table 2. Similarities between small mammals in the temporal distribution of visits measured by Pianka's $a$ (A) and those in visitation pattern for fruit species measured by Spearman's rank correlation (B).

(A) Similarities in temporal distribution of visits (see Appendix for the raw data)

\begin{tabular}{cccccccc}
\hline & $C f$ & $M b$ & $T b$ & $R r$ & $N f$ & $L s$ & $M s$ \\
\hline & $(19)$ & $(33)$ & $(28)$ & $(14)$ & $(23)$ & $(19)$ & $(59)$ \\
$C f$ & & 15 & 10 & 5 & 9 & 9 & 19 \\
$M b$ & 0.478 & & 18 & 10 & 16 & 12 & 32 \\
$T b$ & 0.398 & 0.895 & & 10 & 12 & 12 & 26 \\
$R r$ & 0.000 & 0.017 & 0.017 & & 5 & 7 & 12 \\
$N f$ & 0.000 & 0.018 & 0.017 & 0.678 & & 9 & 23 \\
$L s$ & 0.000 & 0.000 & 0.000 & 0.794 & 0.908 & & 18 \\
$M s$ & 0.002 & 0.043 & 0.031 & 0.952 & 0.983 & 0.925 & \\
\hline
\end{tabular}

(B) Similarities in the visitation pattern for fruit species (see Table 3 for the raw data)

\begin{tabular}{cccccccc}
\hline & $C f$ & $M b$ & $T b$ & $R r$ & $N f$ & $L s$ & $M s$ \\
\hline & $(19)$ & $(33)$ & $(28)$ & $(14)$ & $(23)$ & $(19)$ & $(59)$ \\
$C f$ & & 15 & 10 & 5 & 9 & 9 & 19 \\
$M b$ & $0.251^{*}$ & & 18 & 10 & 16 & 12 & 32 \\
$T b$ & 0.062 & 0.146 & & 10 & 12 & 12 & 26 \\
$R r$ & 0.068 & 0.216 & $0.359^{* *}$ & & 5 & 7 & 12 \\
$N f$ & 0.097 & 0.234 & 0.095 & -0.031 & & 9 & 23 \\
$L s$ & 0.176 & 0.099 & $0.268^{*}$ & 0.231 & 0.048 & & 18 \\
$M s$ & 0.043 & 0.224 & 0.093 & 0.170 & 0.113 & 0.109 & \\
\hline
\end{tabular}

The total number of fruit species visited by each mammal species is shown in the parenthesis on the first line.

Above diagonal: the number of fruit species visited by both the mammal species of each pair; below diagonal: the similarity in the activity pattern (A) and that in the fruit species visit pattern (B).

**: $\mathrm{p}<0.01,{ }^{*} \mathrm{p}<0.05$.

Cf: Callosciurus finlaysonii, Mb: Menetes berdmorei, Tb: Tupaia belangeri, Rr: Rattus remotus, Nf: Niviventer fulvescens, Ls: Leopoldamys sabanus, Ms: Maxomys surifer.

The present results suggest that the differentiation in the visitation patterns for fruit species and feeding time promoted coexistence between some pairs of small mammals in the tropical forest of KY. However, it is known that most small mammal species (including rodents, squirrels and tree shrews) often feed on arthropods as well as fruits (Harrison, 1954, 1961; Lekagul and McNeely, 1977; Corbet and Hill, 1992; Srikosamatara and Hansel, 1996; Emmons, 2000). Thus, further studies on arthropod utilization patterns by small mammals are necessary to understand more comprehensively the factors facilitating coexistence among small mammals.

ACKNOWLEDGMENTS We are grateful to the National Research Council of Thailand and the National Park Division of the Royal Forest Department of Thailand for allowing us to conduct our research in KY. We thank B. Saengthong, S. Chuailua, S. Nakkuntod, S. Sanguanchat, N. Jirawatkavi and all staff of the Thailand
Hornbill Project for supporting our fieldwork and providing encouragement and hospitality. We extend our hearty thanks to the staffs of KY. This research was supported in part by a Research Fund of the Japan Society for the Promotion of Science (\#1357006) and JSPS Research Fellowships for Young Scientists for S. Kitamura.

\section{REFERENCES}

Adler, G.H. \& Kestell D.W. 1998. Fates of neotropical tree seeds influenced by spiny rats (Proechimys semispinosus). Biotropica, 30: 677-681.

Asquith, N.M., Terborgh J., Arnold A.E. \& Riveros C.M. 1999. The fruits the agouti ate: Hymenaea courbaril seed fate when its disperser is absent. Journal of Tropical Ecology, 15: 229-235.

August, P.V. 1983. The role of habitat complexity and heterogeneity in structuring tropical mammal communities. Ecology, 64: 1495-1507. 


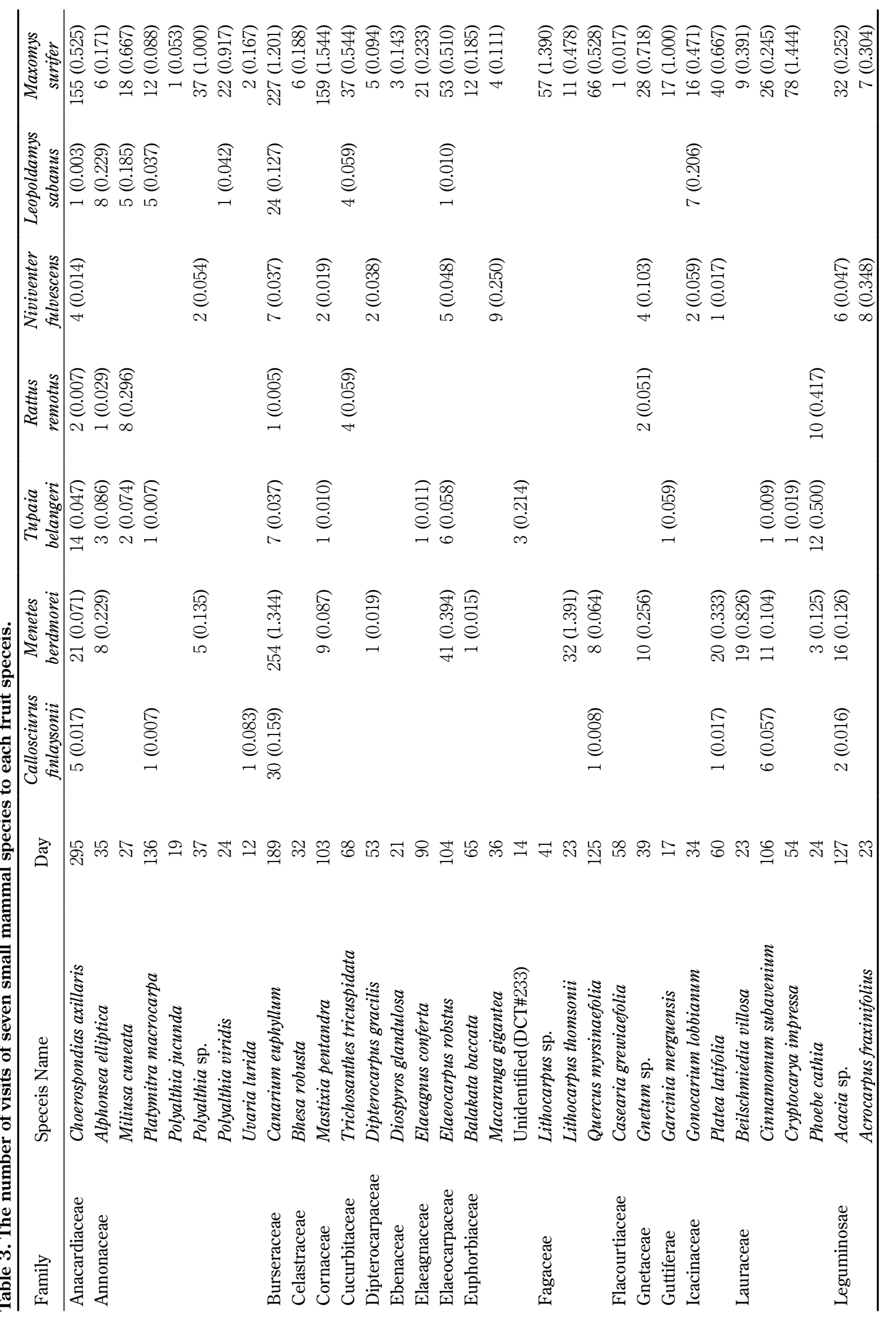




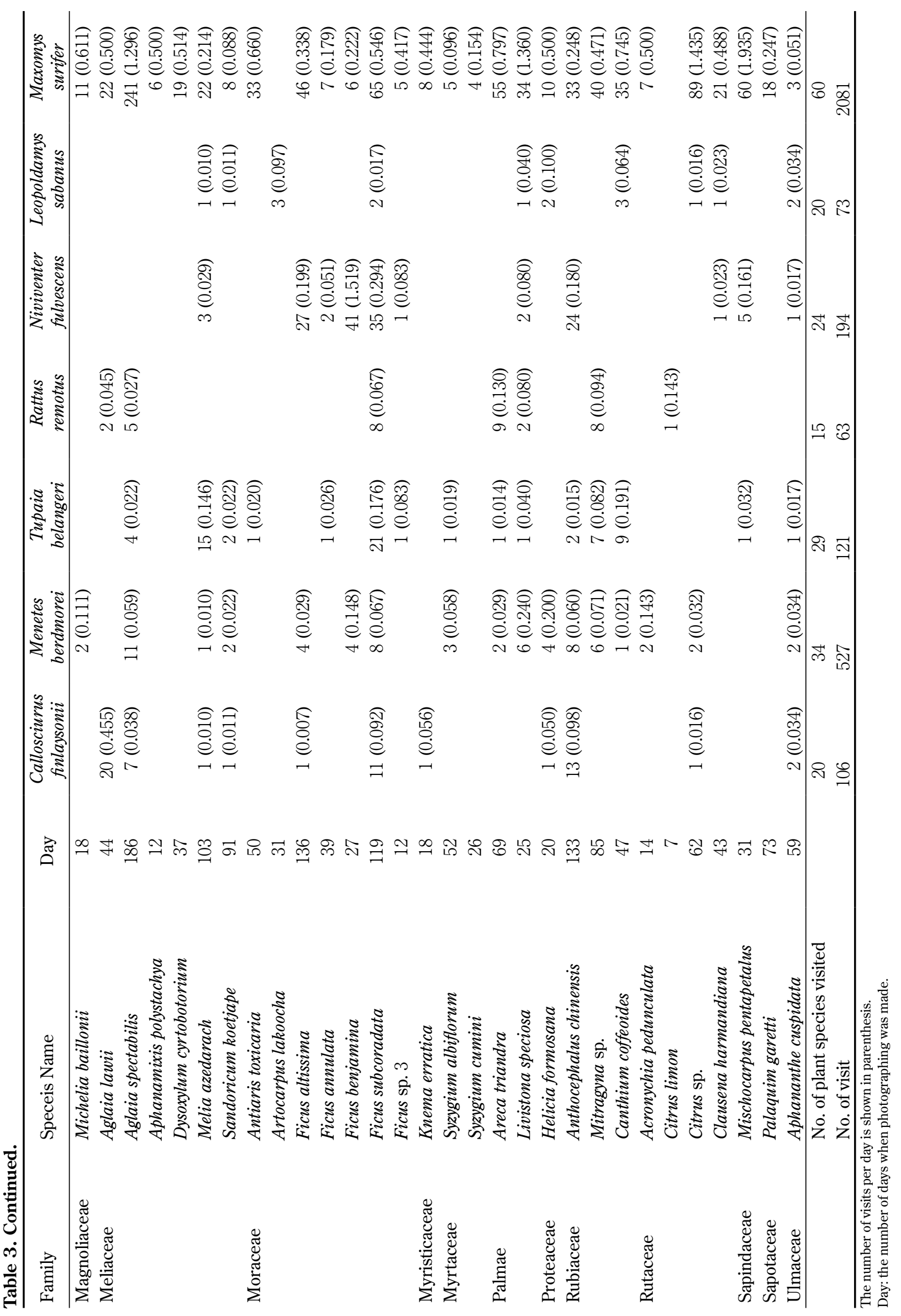


Bartlett, T.Q. 2003. Intragroup and intergroup social interactions in white-handed gibbons. International Journal of Primatology, 24: 239-259.

Blanchong, J.A. \& Smale, L. 2000. Temporal patterns of activity of the unstriped nile rat, Arvicanthis niloticus. Journal of Mammalogy, 81: 595-599.

Brown, J.H., Reichman, O.J. \& Davidson, D.W. 1979. Granivory in desert ecosystems. Annual Review of Ecology and Systematics, 10: 201-227.

Brown, J.S. 1989. Desert rodent community structure: a test of four mechanisms of coexistence. Ecological Monographs, 59: 1-20.

Corbet, G.B. \& Hill, J.E. 1992. The mammals of the Indomalayan region: a systematic review. Oxford University Press, New York.

Emmons, L.H. 1980. Ecology and resource partitioning among nine species of African rain forest squirrels. Ecological Monographs, 50: 31-54.

Emmons, L.H. 2000. TUPAI: A field study of Bornean treeshrews. University of California Press.

Fleming, T.H. 1973. Numbers of mammal species in North and Central American forest communities. Ecology, 54: 555-563.

Griffiths, M. \& van Schaik, C.P. 1993. Camera-trapping: a new tool for the study of elusive rain forest animals. Tropical Biodiversity, 1: 131-135.

Guariguata, M.R., Rosales Adame, J.J. \& Finegan, B. 2000. Seed removal and fate in two selectively logged lowland forests with contrasting protection levels. Conservation Biology, 14: 1046-1054.

Harrison, J.L. 1954. The natural food of some rats and other mammals. The Bulletin of the Raffles Museum, 25: 157-165.

Harrison, J.L. 1961. The Natural food of some Malayan Mammals. The Bulletin of the National Museum (Singapore), 30: 5-18.

Harrison, J.L. 1962. The distribution of feeding habits among animals in a tropical rain forest. Journal of Animal Ecology, 31: 53-63.

Jayasekara, P., Takatsuki, S., Weerasinghe, U.R. \& Wijesundara, S. 2003. Arboreal fruit visitors in a tropical forest in Sri Lanka. Mammal Study, 28: 161-165.

Kawanishi, K. \& Sunquist, M.E. 2004. Conservation status of tigers in a primary rainforest of Peninsular Malaysia. Biological Conservation, 120: 329-344.

Kitamura, S., Suzuki, S., Yumoto, T., Chuailua, P., Plongmai, K., Poonswad, P., Noma, N., Maruhashi, T. \& Suckasam, C. 2005. A botanical inventory of a tropical seasonal forest in Khao Yai National
Park, Thailand: implications for fruit-frugivore interactions. Biodiversity and Conservation, 14: 1241-1262.

Kitamura, S., Suzuki, S., Yumoto, T., Poonswad, P., Chuailua, P., Plongmai, K., Noma, N., Maruhashi, T. \& Suckasam, C. 2004. Dispersal of Aglaia spectabilis, a large-seeded tree species in a moist evergreen forest in Thailand. Journal of Tropical Ecology, 20: 421-427.

Laidlaw, R.K. 2000. Effect of habitat disturbance and protected areas on mammals of Peninsular Malaysia. Conservation Biology, 14: 1639-1648.

Lekagul, B. \& McNeely, J. 1977. Mammals of Thailand. Saha Karn Bhaet Co., Ltd., Bangkok.

M’Closkey, R.T. 1976. Community structure in sympatric rodents. Ecology, 57: 728-739.

Miura, S., Yasuda, M. \& Ratnam, L.C. 1997. Who steals the fruits? Monitoring frugivory of mammals in a tropical rain forest. Malayan Nature Journal, 50: 183-193.

O’Brien, T.G., Kinnaird, M.F. \& Wibisono, H.T. 2003. Crouching tigers, hidden prey: Sumatran tiger and prey populations in a tropical forest landscape. Animal Conservation, 6: 131-139.

Pardini, R. 2004. Effects of forest fragmentation on small mammals in an Atlantic forest landscape. Biodiversity and Conservation, 13: 2567-2586.

Pianka, E.R. 1973. The structure of lizard communities. Annual Review of Ecology and Systematics, 4: 53-74.

Poonswad, P., Chuailua, P., Plongmai, K. \& Nakkuntod, S. 1998. Phenology of some Ficus species and utilization of Ficus sources in Khao Yai National Park, Thailand. In: The Asian Hornbills: Ecology and Conservation, (ed. Poonswad, P), pp. 227-244. Thai Studies in Biodiversity No2, BRT \& BIOTEC, Bangkok.

Robinson, M.F., Smith, A.L. \& Bumrungsri, S. 1995. Small mammals of Thung Yai Naresuan and Huai Kha Khaeng Wildlife Sanctuaries in western Thailand. Natural History Bulletin of the Siam Society, 43: 27-54.

Schoener, T.W. 1974. Resource partitioning in ecological communities. Science, 185: 27-39.

Shanker, K. 2001. The role of competition and habitat in structuring small mammal communities in a tropical montane ecosystem in southern India. Journal of Zoology, London, 253: 15-24.

Smythe, N. 1986. Competition and resource partitioning in the guild of neotropical terrestrial frugivorous mammals. Annual Review of Ecology and Systematics, 
17: 169-188.

Sodhi, N.S., Koh, L.P., Brook, B.W. \& Ng, P.K.L. 2004. Southeast Asian biodiversity: an impending disaster. Trends in Ecology and Evolution, 19: 654-660.

Soule, M.E., Alberts, A.C. \& Bolger, D.T. 1992. The effects of habitat fragmentation on chaparral plants and vertebrates. Oikos, 63: 39-47.

Srikosamatara, S. \& Hansel, T. 1996. Mammals of Khao Yai National Park. Green World Foundation, Bangkok.

Wells, K., Pfeiffer, M., Lakim, M.B. \& Linsenmair, K.E. 2004. Use of arboreal and terrestrial space by a small mammal community in a tropical rain forest in Borneo, Malaysia. Journal of Biogeography, 31: 641-652.

Wu, D.-L., Luo, J. \& Fox, B.J. 1996. A comparison of ground-dwelling small mammal communities in primary and secondary tropical rainforests in China. Journal of Tropical Ecology, 12: 215-230.

Yasuda, M. 2004. Monitoring diversity and abundance of mammals with camera traps: a case study on Mount Tsukuba, central Japan. Mammal Study, 29: 37-46.

Yasuda, M., Ishii, N., Okuda, T. \& Hussein, N.A. 2003. Small mammal community: Habitat preference and effects after selective logging. In: Pasoh: Ecology of a lowland rain forest in Southeast Asia, (eds. Okuda, T., Manokaram, N., Matsumoto, Y., Niiyama, K., Thomas, S.C. \& Ashton, P.S.) pp. 533-546. SpringerVerlag Tokyo, Tokyo.

Yasuda, M., Miura S., Ishii N., Okuda T. \& Hussein N.A. 2005. Fallen fruits and terrestrial vertebrate frugivores: a case study in lowland tropical rainforest in Peninsular Malaysia. In: Seed Fate, (eds. Forget, P.M., Hulme, J.E. \& Wall, S.B.V.), pp. 151-174. CAB International.

Received $27^{\text {th }}$ July 2005

Accepted $24^{\text {th }}$ Jan. 2006 


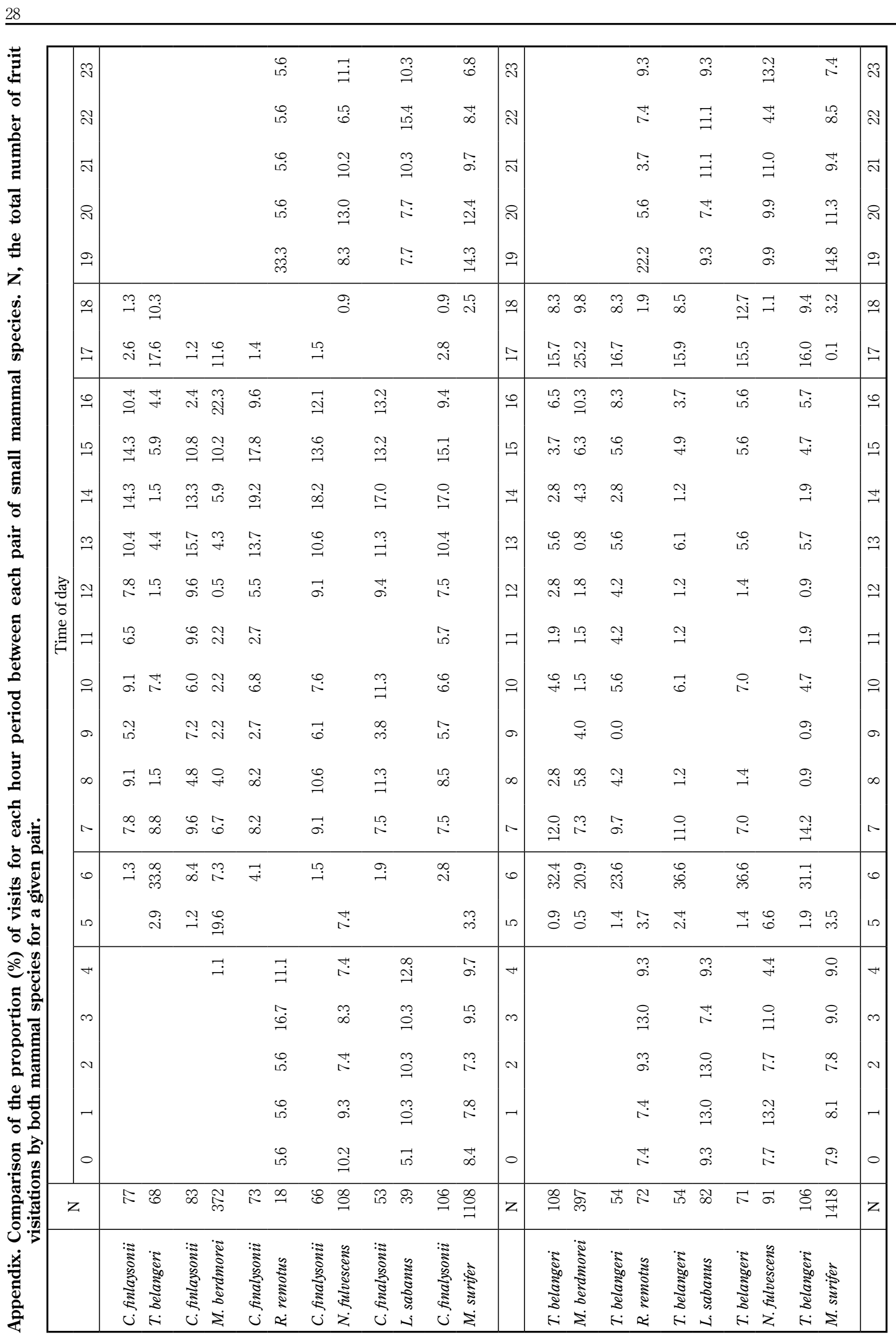




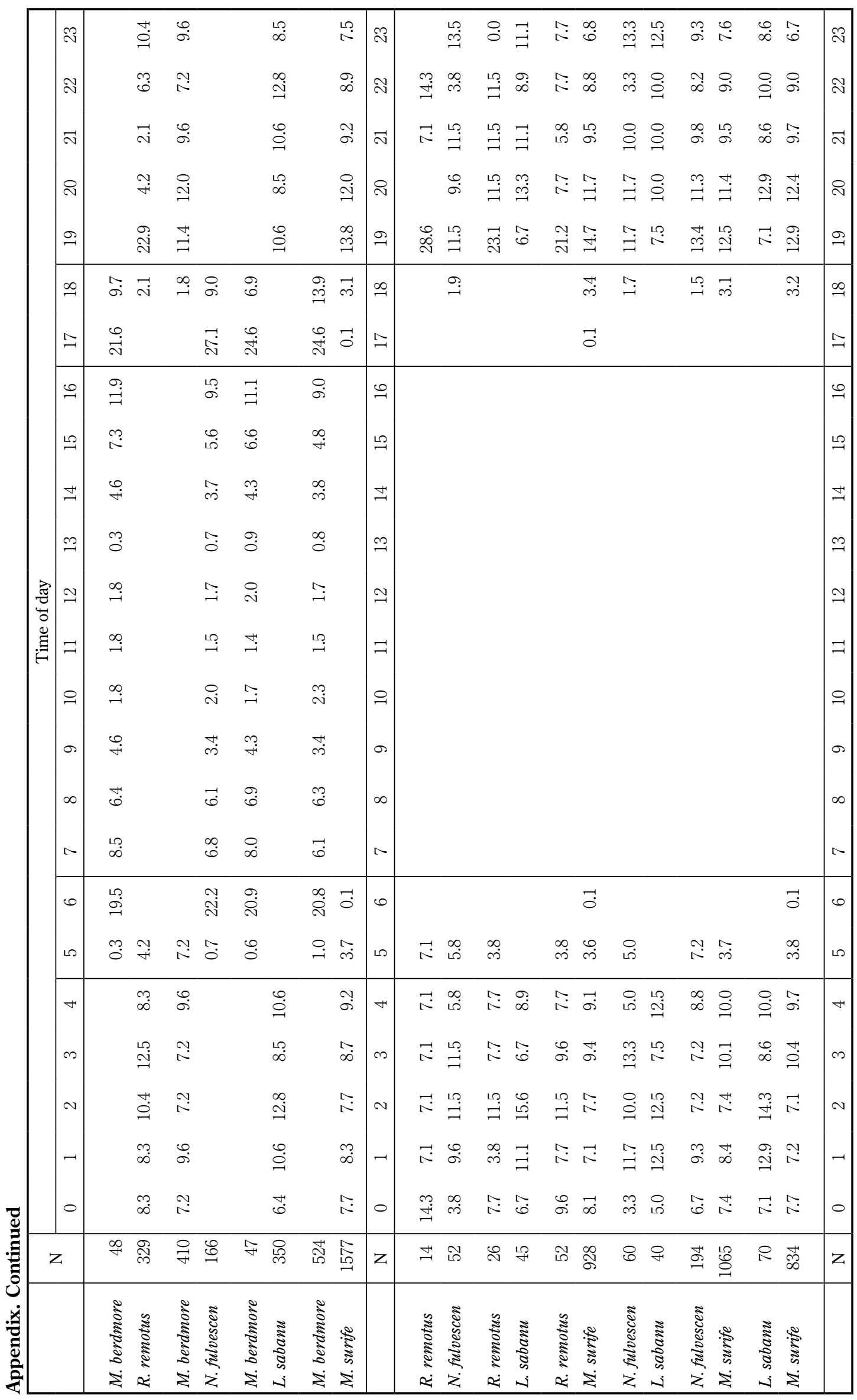

